\title{
Gluten-free/Fiber-enriched Compact Nutritional Supplement Drink
}

National Cancer Institute

\section{Source}

National Cancer Institute. Gluten-free/Fiber-enriched Compact Nutritional Supplement

Drink. NCI Thesaurus. Code C120034.

A g luten-free, calorie-dense, fiber-enriched milkshake-like nutritional supplement drink containing all essential vitamins, minerals, and trace elements, as well as protein, fat and carbohydrates. Upon oral intake, gluten-free, fiber-enriched compact nutritional supplement drink may aid in the prevention of malnutrition and weight loss. The drink is provided in a reduced volume $(125 \mathrm{ml})$ but with the same complete nutrition as the standard drink (200 ml); the reduced volume may increase patient compliance. The fiber, acting as a prebiotic, promotes beneficial bacterial growth in the gastrointestinal (GI) tract, increases digestive health and may reduce the incidence of constipation and/or diarrhea. 